\title{
Effect of Disease Activity on Organ Damage Progression in Systemic Lupus Erythematosus: University of Toronto Lupus Clinic Cohort
}

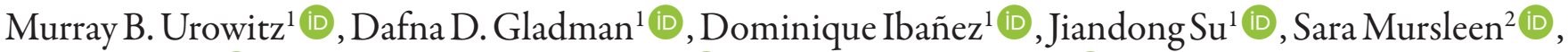 \\ Amyn Sayani ${ }^{2}$ iD, Jorge Alfonso Ross Terres ${ }^{2,3}$ (D), and Sandra Iczkovitz ${ }^{2}$ (D)
}

\begin{abstract}
Objective. To examine the role of disease activity on organ damage over 5 years in patients with active systemic lupus erythematosus (SLE) despite standard of care.

Methods. This analysis of the University of Toronto Lupus Clinic cohort assessed organ damage [measured by Systemic Lupus International Collaborating Clinics/American College of Rheumatology Damage Index (SDI)] in patients with active SLE [SLE Disease Activity Index 2000 (SLEDAI-2K) $\geq 6$ ], using Cox proportional time-independent hazard models. Subgroup analyses were conducted in patients with SLEDAI-2K 6 or 7,8 or 9 , and $\geq 10$ at baseline, and in the overall study population by steroid dose at study entry $(<7.5$ vs $\geq 7.5 \mathrm{mg} /$ day).

Results. Among the overall study population ( $\mathrm{n}=649)$, SDI progression was observed in $209(32.2 \%)$ patients over the 5-year follow-up period. Mean SDI change in patients with a score $>0$ was generally consistent across all SLEDAI-2K subgroups. Multivariable analyses identified age at study start (HR 1.03, $P<0.0001$ ), steroid dose (HR 2.03, $P<0.0001$ ), immunosuppressants (HR 1.44, $P=0.021$ ), and SLEDAI-2K (subgroup analyses HR $1.64-2.03, P=0.0017$ to $<0.0001$ ) as the greatest risk factors for SDI progression, while a study start date after the year 2000 had a protective effect on SDI progression compared with a start date prior to the year 2000 (HR 0.65, $P=0.0004)$.

Conclusion. Patients within the higher SLEDAI-2K subgroups at study entry or receiving high doses of steroids were more likely to have organ damage progression.
\end{abstract}

Key Indexing Terms: disease activity, systemic lupus erythematosus

Systemic lupus erythematosus (SLE) is a chronic autoimmune disorder characterized by periods of active disease and remis$\operatorname{sion}^{1}$. It can affect a wide range of organ systems, and may result in organ damage related to the disease process and medication toxicity, particularly corticosteroids $\mathrm{s}^{1,2,3}$. Organ damage has a substantial effect on patients and is associated with an increased risk of further organ damage ${ }^{4}$, increased morbidity and mortality ${ }^{45,6}$, increased difficulty in performing daily activities ${ }^{7}$,

This study was funded by GlaxoSmithKline Inc. (GSK; study number 201390).

${ }^{1}$ M.B. Urowitz, MD, D.D. Gladman, MD, D. Ibañez, MSc, J. Su, MSc, Centre for Prognosis Studies in Rheumatic Diseases, Toronto Western

Hospital, Toronto, Ontario, Canada; ${ }^{2}$ S. Mursleen, MSc, A. Sayani, PhD,

S. Iczkovitz, MSc, GlaxoSmithKline Inc., Toronto, Ontario, Canada;

${ }^{3}$ J.A.R. Terres, MD, GlaxoSmithKline Inc., Toronto, Ontario, Canada, and

GlaxoSmithKline Inc., Philadelphia, Pennsylvania, USA.

JART and SM are employees of GSK. AS was an employee of GSK at the time of the study. AS and JART hold stocks in GSK. SI was an employee of GSK during the development of the manuscript. MBU has received consulting fees and research grants from $G S K, U C B$, and Eli Lilly. DDG reports consulting for GSK, BMS, Janssen, UCB, and Eli Lilly.

Address correspondence to Prof. M.B. Urowitz, Toronto Western Hospital, 399 Bathurst Street, IE409, Toronto, ON M5T 2S8, Canada.

Email:m.urowitz@utoronto.ca.

Full Release Article. For details see Reprints/Permissions at jrheum.org Accepted for publication March 18, 2020. and increased economic burden to the healthcare system ${ }^{8}$. Given its substantive effect and the fact that SLE organ damage is irreversible, it is important to identify and reduce factors associated with its accrual.

Previously published research examining factors associated with an increased risk of organ damage was derived from lupus cohort analyses that include all patients with SLE, regardless of baseline disease activity ${ }^{9,10,11}$. The clinical burden and effect of active, uncontrolled SLE [defined as SLE Disease Activity Index 2000 (SLEDAI-2K) $\geq 6$ despite standard of care] on long-term organ damage, however, have not been well studied. Therefore, more research into the clinical burden and effect of disease activity is required.

To address this question, data from a cohort of patients from the University of Toronto Lupus Clinic (UTLC) who were more representative of patients included in SLE randomized controlled trials (RCT) ${ }^{12,13,14,15,16}$, were extracted from the UTLC database and analyzed in the present research. As per the inclusion criteria for SLE RCT, patients with active, uncontrolled SLE (SLEDAI-2K $\geq 6$ ) despite standard of care were included, but those with severe lupus nephritis or central nervous system (CNS) lupus were excluded, again to mimic the criteria within RCT. The primary objective of this analysis was to evaluate the effect of disease activity on organ damage 
progression beyond baseline organ damage at study start, in patients from the UTLC cohort.

\section{MATERIALS AND METHODS}

Research setting. The UTLC is the largest cohort of patients with SLE in Canada and at the time of this analysis, 1753 patients were included within the UTLC database. To be eligible for inclusion in the UTLC, patients must have had a clinical diagnosis of SLE, met $\geq 4$ of the American College of Rheumatology (ACR) criteria for SLE, or met 3 criteria and had a positive biopsy for SLE. Patient data, including history, physical examination, and laboratory variables, were collected every 2-6 months according to a well-defined protocol and stored on a computer database ${ }^{17}$. SLEDAI-2K data were collected prospectively, and adjusted mean SLEDAI-2K (AMS) was determined by calculating the area under the curve of the SLEDAI-2K over time ${ }^{10}$. The Systemic Lupus International Collaborating Clinics (SLICC)/ACR Damage Index (SDI), the validated measure for monitoring and quantifying irreversible organ damage in patients with SLE was collected on a yearly basis ${ }^{18}$. The study protocol was approved by the University Health Network Research Ethics Board (approval number MBU REB\# 14-7612-BE), and approval of the UTLC protocol is obtained annually.

Study design and patient selection. This posthoc analysis (GSK study number 201390) was a single-center, longitudinal, observational cohort study using prospectively collected data from patients with SLE who were monitored and assessed within the UTLC from January 1, 1980, to December 31, 2013. All patients provided informed consent for the collection of clinical and laboratory data obtained as part of their routine clinical care for use in future research studies. Eligible patients had active disease, defined as SLEDAI-2K $\geq 6$, and received regular follow-up (defined as having been in the clinic for $\geq 5$ visits) over a minimum of 3 years, with no more than an 18 -month consecutive period without a clinic visit. Patients were excluded if, at study entry, they had severe active lupus kidney disease (proteinuria $>6 \mathrm{~g} / 24 \mathrm{~h}$, or serum creatinine $>2.5 \mathrm{mg} / \mathrm{dL}$ ) or severe active CNS lupus (defined by the presence of seizures, psychosis, organic brain syndrome, cerebrovascular accident, cerebritis, or CNS vasculitis), received prednisone $>100 \mathrm{mg}$ /day, required hemodialysis, or received a kidney transplant. Study entry was defined as the first occurrence of SLEDAI- $2 \mathrm{~K} \geq 6$ that met the inclusion and exclusion criteria.

Study endpoints. The primary endpoints were organ damage progression within 5 years from study entry. Organ damage was documented according to the number of patients with SDI score $>0$, and damage progression was defined as any increase in SDI score $e^{5,19,20}$.

Data analyses. Descriptive analyses were conducted for the overall study population (SLEDAI-2K $\geq 6$ ), as well as for 3 mutually exclusive subgroups: patients with mildly active SLE (SLEDAI-2K 6 or 7), moderately active SLE (SLEDAI-2K 8 or 9), and highly active SLE (SLEDAI $2 \mathrm{~K} \geq 10$ ). An additional subgroup analysis evaluated patients with SLEDAI-2K $\geq 6$ and steroid doses (prednisone equivalent) $\geq 7.5 \mathrm{mg} /$ day at study entry. These subgroups were selected to examine the effect of varying levels of disease activity on organ damage.

Demographics were assessed at study entry. Clinical characteristics, including SLEDAI-2K score, AMS, and SDI score, were summarized at study entry and after 1, 3, and 5 years. Kaplan-Meier curves were plotted to estimate long-term organ damage progression over a 5 -year period with respect to SDI score, SLEDAI-2K score, and steroid dose at study entry.

To identify significant predictors of organ damage, univariate and multivariable Cox proportional regression models were constructed, and a large number of variables of interest incorporated, with adjustment for patient demographics, baseline organ damage, baseline treatment, and era of study entry (before or after the year 2000). Separate analyses were carried out for each disease activity or steroid dose subgroup; all predictors used in the analysis were time independent. Proportionalities of predictors were investigated using Schoenfeld residuals; linearity for continuous variables was checked using Martingale residuals. Variables in the multivariable regression model were selected by the step-down method with lowest Akaike information criterion in the final model. Interactions among predictor variables were investigated, and nonstatistical significance was ensured. All analyses were conducted in SAS version 9.3 (SAS Institute), and $P<0.05$ was considered significant.

\section{RESULTS}

Study population. After applying the inclusion and exclusion criteria for this analysis, a total of 649 patients were eligible for this study. The overall study population of 649 patients was predominantly female (90.8\%) and white (70.0\%; Table 1$)$. Mean (SD) age at study entry was 37.6 (13.6) years. The decade with the most study entries was the 2000s (47.9\%). Within the overall study population, $68.9 \%(\mathrm{n}=447 / 649)$ of patients had steroid use at baseline $\geq 7.5 \mathrm{mg} /$ day, compared with $31.1 \%(\mathrm{n}=202 / 649)$ of patients with $<7.5 \mathrm{mg} /$ day or no steroid use at baseline. Mean (SD) SLEDAI-2K at study entry was $11.2(4.8)$ in the overall study population and 10.5 (5.2) in the SLEDAI-2K $\geq 6$ group with steroid use $\geq 7.5 \mathrm{mg} /$ day. The majority of patients had skin and immunological SLEDAI-2K organ domain involvement at baseline ( $49.5 \%$ and $71.5 \%$, respectively), whereas involvement of the renal (42.5\%), musculoskeletal (29.3\%), vascular (19.1\%), hematologic (7.1\%), fever (6.5\%), serosal (5.7\%), and CNS $(0.9 \%)$ domains was less common. The use of steroids, antimalarials, and immunosuppressants at baseline was $67.0 \%$, $51.3 \%$, and $32.2 \%$, respectively.

Disease activity. SLEDAI-2K score and AMS decreased from study entry at 1,3 , and 5 years post study entry in all groups. For all groups, the percentage of patients receiving steroids increased at 1-year post study entry and subsequently decreased at the 3- and 5-year follow-ups (Supplementary Table 1A-D, available with the online version of this article).

Organ damage. In the overall study population, 32.5\% $(\mathrm{n}=211 / 649)$ of patients had an SDI score $>0$ at baseline, and the mean (SD) SDI score of these patients was 2.0 (1.5). The percentage of patients with an SDI score $>0$ increased at each interval (1,3, and 5 years post study entry), within each SLEDAI-2K subgroup (Supplementary Table 1A-D, available with the online version of this article). Overall, $32.2 \%$ $(n=209 / 649)$ of patients experienced SDI progression within 5 years of study entry. Of patients with an SDI score $>0$ at baseline, 38.9\% ( $\mathrm{n}=82 / 211)$ experienced SDI progression within 5 years. Of patients with an SDI score $=0$ at baseline $(\mathrm{n}=438 / 649), 29.0 \%(\mathrm{n}=127 / 438)$ experienced SDI progression within 5 years. Mean (SD) SDI in patients with an SDI score $>0$ in the overall study population increased from 2.0 (1.5) at 1 -year post study entry, to $2.2(1.5)$ at 5 -year post study entry (Supplementary Table 1A). Similar increases in mean (SD) SDI from 1-year post study entry to 5-year post study entry can be observed in all the SLEDAI-2K subgroups in patients with an SDI score $>0$ (Supplementary Table 1B-D).

Univariate Cox time-independent covariate analyses identified steroid dose $\geq 7.5 \mathrm{mg} /$ day (HR $1.87, P=0.0002$ ), SDI score at study entry (HR 1.15, $P=0.0014$ ), and older age (HR $1.02, P<0.0001$; Table $2 \mathrm{~A}$ ) as risk factors for SDI progression, while later entry into the study had a protective effect for SDI 


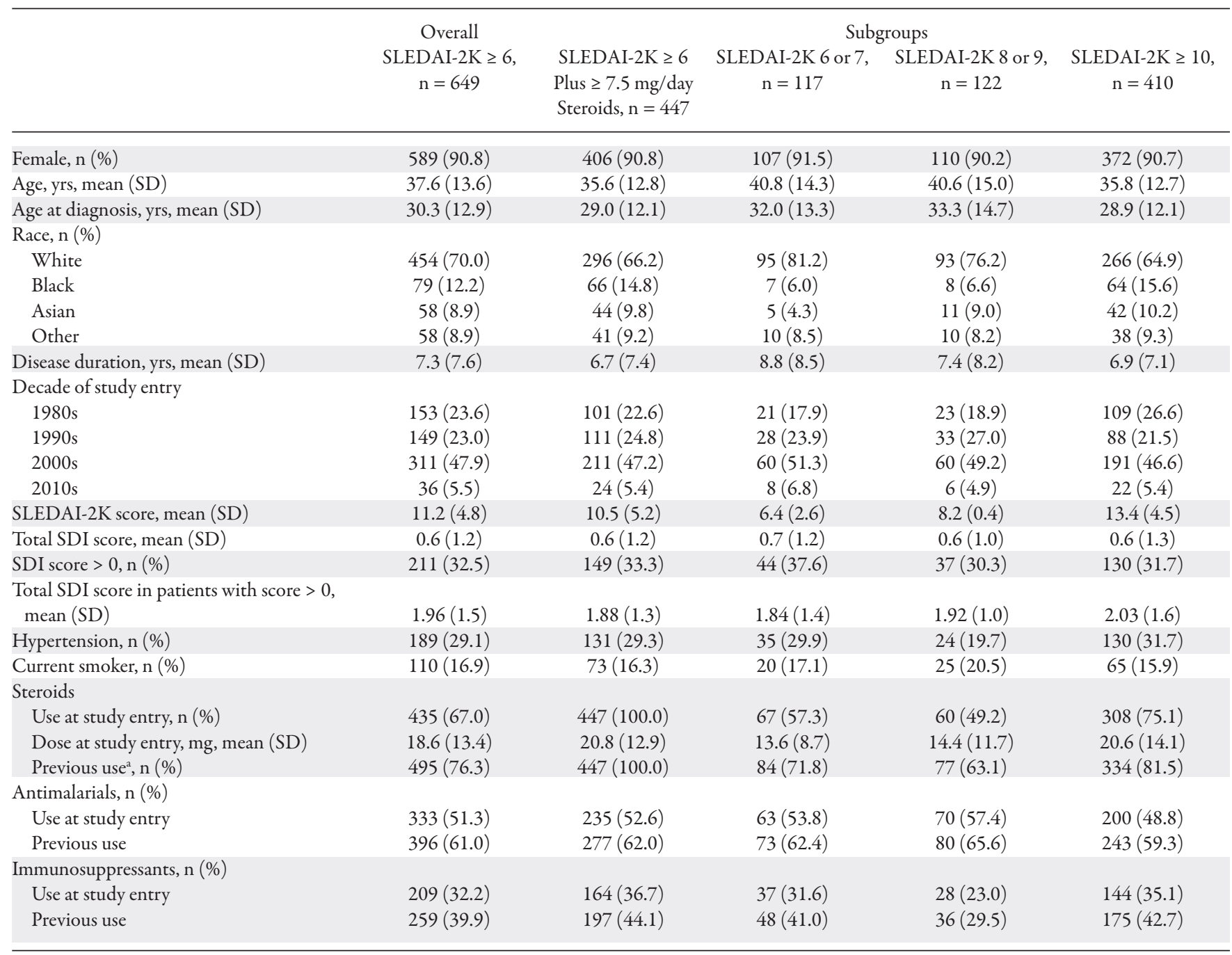

${ }^{a}$ Includes any use before study entry and use at study entry. SDI: Systemic Lupus International Collaborating Clinics/American College of Rheumatology Damage Index; SLEDAI-2K: Systemic Lupus Erythematosus Disease Activity Index 2000.

progression in the overall study population (Table $2 \mathrm{~A}-\mathrm{D}$ ). A higher SLEDAI-2K was predictive of SDI progression, particularly for SLEDAI-2K $\geq 10$, compared with entry SLEDAI-2K $=6$ or 7 (HR 1.70, $P=0.011$; Table $2 \mathrm{~B})$, SLEDAI-2K $\geq 8$ compared with entry SLEDAI-2K $=6$ or 7 (HR 1.56, $P=0.0304$; Table 2C), and entry SLEDAI-2K $<10$ (HR 1.60, $P=0.0023$; Table 2D).

Steroid dose $\geq 7.5 \mathrm{mg} /$ day (HR 2.03, $P<0.0001$ ) was predictive of progression of damage (Table $2 \mathrm{~A}$ ). In addition, older age, immunosuppressive use, and study entry prior to the year 2000 were risk factors for damage progression (Table 2A-D). Multivariable analyses identified entry SLEDAI-2K $\geq 10$ was predictive when compared with entry SLEDAI-2K $=6$ or 7 (HR 1.91, $P=0.0021$; Table 2B), as was entry SLEDAI-2K $\geq 8$ when compared with entry SLEDAI-2K $=6$ or 7 (HR 1.70, $P=0.0104$; Table 2C), and entry SLEDAI-2K $\geq 10$ compared with SLEDAI-2K $<10($ HR 1.78, $P=0.0003$; Table 2D).

In Kaplan-Meier curves, the percentage of patients with
SDI progression was generally higher in patients with a higher SLEDAI-2K at study entry (Figure 1A). Organ damage was greater in patients with steroid doses $\geq 7.5 \mathrm{mg} /$ day at study entry compared with patients receiving a dose $<7.5 \mathrm{mg} /$ day (Figure 1B). A higher SDI score at study entry was also associated with increased damage progression (Figure 1C). The log-rank test reported significant differences in all 3 group comparisons.

\section{DISCUSSION}

The UTLC has contributed to the understanding of the assessment, monitoring, and treatment of underlying disease activity in patients with SLE ${ }^{17,18,21,22}$. A key objective of this study was to analyze eligible patients from the UTLC cohort whose characteristics were similar to those of patients included within SLE RCT, namely patients with active SLE that was uncontrolled despite concomitant standard of care. This analysis therefore included patients with SLEDAI-2K $\geq 6$ as the overall study population, and additional analyses were conducted on 3 subgroups with 
Table $2 A$. Significant factors identified by univariate and multivariable Cox time-independent analysis for SDI progression in 5 years: steroid dose high versus low.

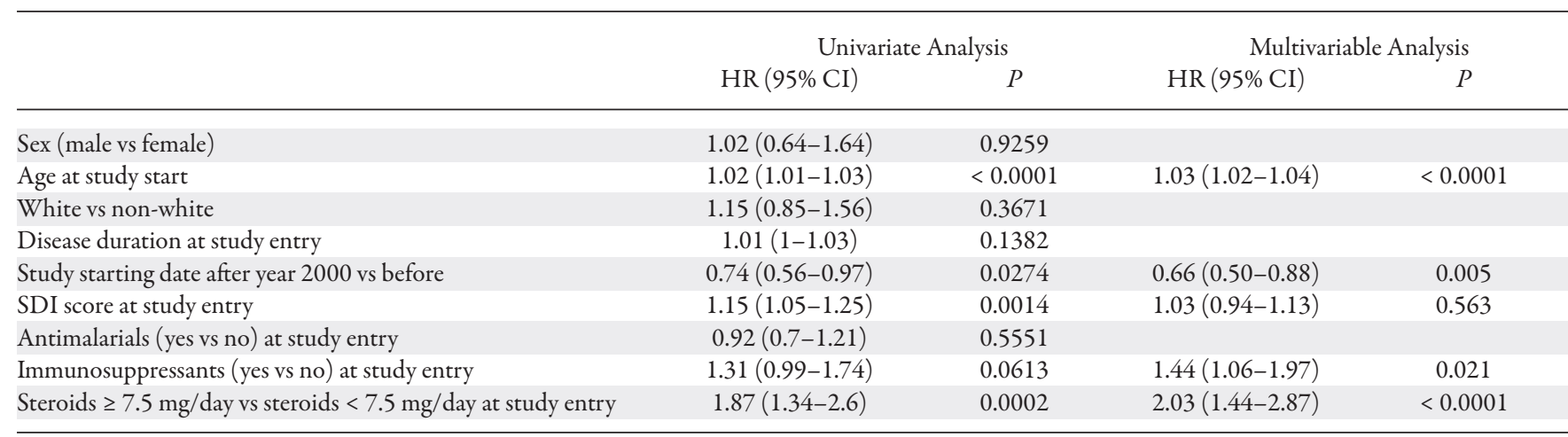

Analysis conducted with data from patients from the overall study population who experienced organ damage progression within 5 years of study entry $(n=209 / 649)$; all patients' data were used.

Table 2B. Significant factors identified by univariate and multivariable Cox time-independent analysis for SDI progression in 5 years: baseline SLEDAI-2K 8 or 9 , SLEDAI- $2 \mathrm{~K} \geq 10$, versus 6 or 7 .

Univariate Analysis

HR $(95 \% \mathrm{CI}) \quad P$

$\begin{array}{cccc}1.02(0.64-1.64) & 0.9259 & & \\ 1.02(1.01-1.03) & <0.0001 & 1.03(1.02-1.04) & <0.0001 \\ 1.15(0.85-1.56) & 0.3671 & & \\ 1.01(1-1.03) & 0.1382 & & \\ 0.74(0.56-0.97) & 0.0274 & 0.66(0.50-0.88) & 0.0054 \\ 1.15(1.05-1.25) & 0.0014 & 1.03(0.94-1.13) & 0.4715 \\ 0.92(0.7-1.21) & 0.5551 & & \\ 1.31(0.99-1.74) & 0.0613 & 1.59(1.17-2.17) & 0.0032 \\ 1.12(0.67-1.88) & 0.6663 & 1.15(0.69-1.93) & 0.589 \\ 1.70(1.13-2.56) & 0.011 & 1.91(1.26-2.90) & 0.0021\end{array}$

Table 2C. Significant factors identified by univariate and multivariable Cox time-independent analysis for SDI progression in 5 years: baseline SLEDAI-2K $\geq 8$ versus $<8$.

\begin{tabular}{|c|c|c|c|c|}
\hline & $\mathrm{HR}(95 \% \mathrm{CI})$ & $P$ & $\operatorname{HR}(95 \% \mathrm{CI})$ & $P$ \\
\hline Sex (male vs female) & $1.02(0.64-1.64)$ & 0.9259 & & \\
\hline Age at study start & $1.02(1.01-1.03)$ & $<0.0001$ & $1.02(1.01-1.03)$ & $<0.0001$ \\
\hline White vs non-white & $1.15(0.85-1.56)$ & 0.3671 & & \\
\hline Disease duration at study entry & $1.01(1-1.03)$ & 0.1382 & & \\
\hline Antimalarials (yes vs no) at study entry & $0.92(0.7-1.21)$ & 0.5551 & & \\
\hline Immunosuppressants (yes vs no) at study entry & $1.31(0.99-1.74)$ & 0.0613 & $1.64(1.20-2.23)$ & 0.0017 \\
\hline Entry SLEDAI-2K $\geq 8$ vs entry SLEDAI-2K 6 or 7 & $1.56(1.04-2.34)$ & 0.0304 & $1.70(1.13-2.55)$ & 0.0104 \\
\hline
\end{tabular}

high disease activity: patients with SLEDAI-2K scores of 6 or 7,8 or 9 , and $\geq 10$. These groups were mutually exclusive to improve understanding of the effect of levels of disease activity on organ damage progression. An additional subgroup evaluated patients with SLEDAI-2K $\geq 6$ and a steroid dose $\geq 7.5 \mathrm{mg} /$ day at study entry.

In this analysis, higher SLEDAI-2K score, steroid use, older age at study entry, and immunosuppressive treatment at study entry were all found to be predictive of organ damage in both univariate and multivariable analyses. Higher SDI score at study entry was also predictive of organ damage within the univariate analysis; however, this was not reflected within the multivariable analysis, possibly due to interaction with age and disease duration. Age at diagnosis and its correlation to organ damage has been studied over previous years ${ }^{23}$ and has generally shown similar results to this study ${ }^{23,24,25}$. Organ damage was more common in patients receiving steroids $\geq 7.5 \mathrm{mg} /$ day at study entry compared with patients receiving steroids $<7.5 \mathrm{mg} /$ day at 
Table 2D. Significant factors identified by univariate and multivariable Cox time-independent analysis for SDI progression in 5 years: SLEDAI-2K $\geq 10$ versus $<10$.

\begin{tabular}{lccc}
\hline & \multicolumn{2}{c}{ Univariate Analysis } & Multivariable Analysis \\
& HR $(95 \% \mathrm{CI})$ & $P$ & HR $(95 \% \mathrm{CI})$ \\
\hline Sex (male vs female) & $1.02(0.64-1.64)$ & 0.9259 & \\
Age at study start & $1.02(1.01-1.03)$ & $<0.0001$ & $1.03(1.02-1.04)$ \\
White vs non-white & $1.15(0.85-1.56)$ & 0.3671 & \\
Disease duration at study entry & $1.01(1-1.03)$ & 0.1382 & \\
Study starting date after year 2000 vs before & $0.74(0.56-0.97)$ & 0.0274 & $0.66(0.49-0.88)$ \\
SDI score at study entry & $1.15(1.05-1.25)$ & 0.0014 & $1.03(0.94-1.13)$ \\
Antimalarials (yes vs no) at study entry & $0.92(0.7-1.21)$ & 0.5551 & 0.0054 \\
Immunosuppressants (yes vs no) at study entry & $1.31(0.99-1.74)$ & 0.0613 & $1.59(1.17-2.17)$ \\
Entry SLEDAI-2K $\geq 10$ vs entry SLEDAI-2K 6, 7, 8, or 9 & $1.60(1.18-2.17)$ & 0.0023 & $1.78(1.30-2.43)$ \\
\hline
\end{tabular}

SDI: Systemic Lupus International Collaborating Clinics/American College of Rheumatology Damage Index; SLEDAI-2K: Systemic Lupus Erythematosus Disease Activity Index 2000.

A

Damage Progression by SLEDAI-2K

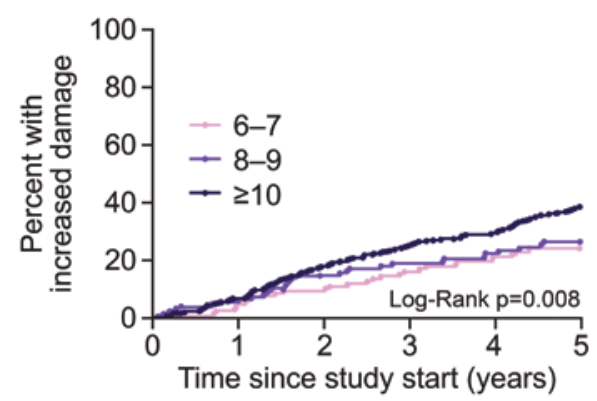

\begin{tabular}{|lccccc|}
\hline & \multicolumn{5}{c|}{ Percent with increased damage } \\
SLEDAI-2K & 1 year & 2 years & 3 years & 4 years & 5 years \\
\hline $6-7$ & 5.1 & 9.4 & 16.2 & 20.5 & 23.1 \\
$8-9$ & 6.6 & 14.8 & 18.9 & 22.1 & 25.4 \\
$\geq 10$ & 6.8 & 18.0 & 25.4 & 29.3 & 36.8 \\
\hline
\end{tabular}

B

\section{Damage Progression by Steroids}

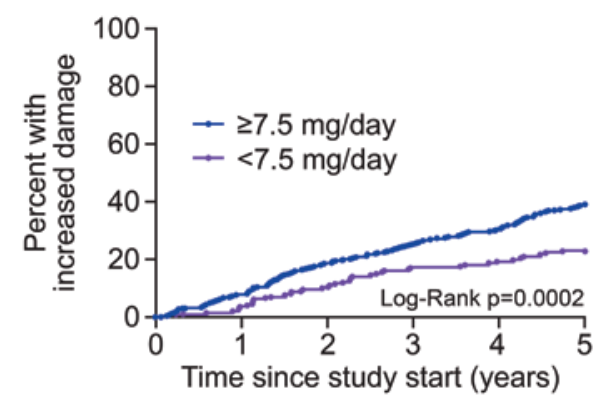

\begin{tabular}{|lccccc|}
\hline & \multicolumn{5}{c|}{ Percent with increased damage } \\
Steroids & 1 year & 2 years & 3 years & 4 years & 5 years \\
\hline$<7.5 \mathrm{mg} /$ day & 3.5 & 9.9 & 16.8 & 18.8 & 21.8 \\
$\geq 7.5 \mathrm{mg} /$ day & 7.8 & 18.6 & 25.1 & 29.8 & 36.9 \\
\hline
\end{tabular}

C

Damage Progression by Baseline SDI

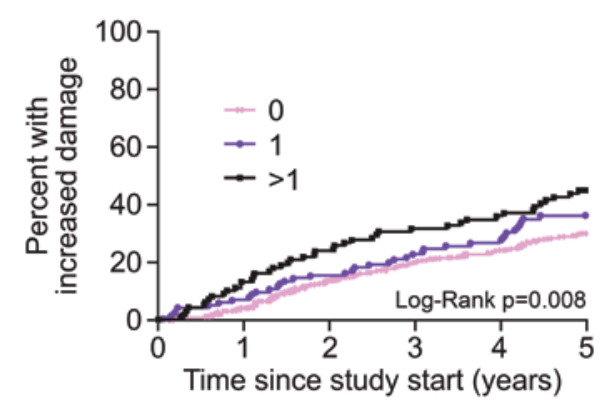

\begin{tabular}{|lccccc|}
\hline \multicolumn{5}{|c|}{ Percent with increased damage } \\
SDI & 1 year & 2 years & 3 years & 4 years & 5 years \\
\hline 0 & 4.6 & 13.9 & 20.1 & 24.0 & 29.0 \\
1 & 7.4 & 15.7 & 23.1 & 26.9 & 34.3 \\
$>1$ & 13.6 & 24.3 & 32.0 & 35.9 & 43.7 \\
\hline
\end{tabular}

Figure 1. Kaplan-Meier curves for organ damage progression by (A) SLEDAI-2K score, (B) steroid use, and (C) SDI score at study entry, in patients with SLEDAI-2K $\geq 6$. SDI: Systemic Lupus International Collaborating Clinics/American College of Rheumatology Damage Index; SLEDAI-2K: Systemic Lupus Erythematosus Disease Activity Index 2000. 
study entry. The detrimental effect of higher steroid doses is in agreement with previous analyses of the complete UTLC population, the SLICC Inception Cohort, and the Hopkins Lupus Cohort $^{4,10,26}$. In the Hopkins Lupus Cohort, age, SLEDAI, and current steroid dose (defined in that study as $1-9 \mathrm{mg} /$ day, 10-19 $\mathrm{mg} /$ day, and $\geq 20 \mathrm{mg} /$ day) were all found to be predictors of organ damage ${ }^{10}$, as well as a history of hypertension (HTN). Results from the SLICC Inception Cohort were similar, with age, African American race, SLEDAI-2K score, steroid use, and HTN all predictive of organ damage accrual. However, analyses of the entire UTLC identified other predictors of organ damage in addition to steroid use, including AMS (HR 1.06) and disease duration (HR 1.05) $)^{27}$, which were factors not found to be associated with organ damage in this study of patients with SLEDAI- $2 \mathrm{~K} \geq 6$. This difference may be due to the longer duration of follow-up within the analysis of the entire UTLC (mean $8.0 \mathrm{yrs})$.

There are some limitations to our study. The percentage of patients who received steroids and immunosuppressants represents the percentage of patients taking these medications at the time of inclusion in the study; however, it is likely that at subsequent visits, treatments were added or increased because of patients' new diagnosis of active disease. Strengths of this study include the large number of patients monitored prospectively, as well as the inclusion of patients within this cohort who are broadly reflective of those generally included within SLE RCT. Further, although the proteinuria cutoff for exclusion of patients with severe active lupus kidney disease was the accepted limit of $>6 \mathrm{~g} / 24 \mathrm{~h}$, patients with $\geq 2$ to $\leq 6 \mathrm{~g} / 24 \mathrm{~h}$ would still be considered as having significant renal disease. However, the number of patients with proteinuria $\geq 2$ to $\leq 6 \mathrm{~g} / 24 \mathrm{~h}$ was small $(\mathrm{n}=7)$. Additionally, the proportion of patients receiving antimalarials at baseline in this study was $51.3 \%$, which is lower than what is typically reported in RCT of SLE (> 65\% $)^{12,13,14}$. This discrepancy is likely a result of several patients in this study having been initially recruited in the 1970s and 1980s, when the use of antimalarials for SLE was not as widespread ${ }^{28}$.

In summary, patients with highly active disease, with organ damage, or receiving high doses of steroids at study entry were more likely to have increased organ damage over time. The association between use of higher doses of steroids with organ damage provides further evidence in support of the need for steroid-sparing therapies ${ }^{29,30}$ and control of disease activity without reliance on steroids ${ }^{10}$. This study therefore demonstrates a need for better disease control among patients with active SLE.

\section{ACKNOWLEDGMENT}

The authors wish to thank Nicole Anderson (Centre for Prognosis Studies in Rheumatic Diseases, Toronto Western Hospital) for her contributions to this study. Medical writing support was provided by Emma Hargreaves, MA, and Jennie McLean, PhD, of Fishawack Indicia Ltd, UK, and was funded by GSK.

\section{ONLINE SUPPLEMENT}

Supplementary material accompanies the online version of this article.

\section{REFERENCES}

1. Zonana-Nacach A, Barr SG, Magder LS, Petri M. Damage in systemic lupus erythematosus and its association with corticosteroids. Arthritis Rheum 2000;43:1801-8.

2. Rahman A, Isenberg DA. Systemic lupus erythematosus. N Engl J Med 2008;358:929-39.

3. Zonana-Nacach A, Camargo-Coronel A, Yanez P, de Lourdes Sanchez M, Jimenez-Balderas FJ, Aceves-Avila J, et al. Measurement of damage in 210 Mexican patients with systemic lupus erythematosus: relationship with disease duration. Lupus 1998;7:119-23.

4. Bruce IN, O’Keeffe AG, Farewell V, Hanly JG, Manzi S, Su L, et al. Factors associated with damage accrual in patients with systemic lupus erythematosus: results from the Systemic Lupus International Collaborating Clinics (SLICC) Inception Cohort. Ann Rheum Dis 2015;74:1706-13.

5. Gladman DD, Goldsmith CH, Urowitz MB, Bacon P, Fortin P, Ginzler E, et al. The Systemic Lupus International Collaborating Clinics/American College of Rheumatology (SLICC/ACR) Damage Index for systemic lupus erythematosus international comparison. J Rheumatol 2000;27:373-6.

6. Nived O, Jonsen A, Bengtsson AA, Bengtsson C, Sturfelt G. High predictive value of the Systemic Lupus International Collaborating Clinics/American College of Rheumatology Damage Index for survival in systemic lupus erythematosus. J Rheumatol 2002;29:1398-400.

7. Bjork M, Dahlstrom O, Wettero J, Sjowall C. Quality of life and acquired organ damage are intimately related to activity limitations in patients with systemic lupus erythematosus. BMC Musculoskelet Disord 2015;16:188.

8. Jönsen A, Bengtsson AA, Hjalte F, Petersson IF, Willim M, Nived O. Total cost and cost predictors in systemic lupus erythematosus - 8-years follow-up of a Swedish inception cohort. Lupus 2015;24:1248-56.

9. Lopez R, Davidson JE, Beeby MD, Egger PJ, Isenberg DA. Lupus disease activity and the risk of subsequent organ damage and mortality in a large lupus cohort. Rheumatology 2012;51:491-8.

10. Petri M, Purvey S, Fang H, Magder LS. Predictors of organ damage in systemic lupus erythematosus: the Hopkins Lupus Cohort. Arthritis Rheum 2012;64:4021-8.

11. Taraborelli M, Cavazzana I, Martinazzi N, Lazzaroni MG, Fredi M, Andreoli L, et al. Organ damage accrual and distribution in systemic lupus erythematosus patients followed-up for more than 10 years. Lupus 2017;26:1197-204.

12. Furie R, Petri M, Zamani O, Cervera R, Wallace DJ, Tegzová D, et al; BLISS-76 Study Group. A phase III, randomized, placebo-controlled study of belimumab, a monoclonal antibody that inhibits B lymphocyte stimulator, in patients with systemic lupus erythematosus. Arthritis Rheum 2011;63:3918-30.

13. Navarra SV, Guzman RM, Gallacher AE, Hall S, Levy RA, Jimenez RE, et al; BLISS-52 Study Group. Efficacy and safety of belimumab in patients with active systemic lupus erythematosus: a randomised, placebo-controlled, phase 3 trial. Lancet 2011;377:721-31.

14. Stohl W, Schwarting A, Okada M, Scheinberg M, Doria A, Hammer AE, et al. Efficacy and safety of subcutaneous belimumab in systemic lupus erythematosus: a fifty-two-week randomized, double-blind, placebo-controlled study. Arthritis Rheum 2017;69:1016-27.

15. Zhang F, Bae SC, Bass D, Chu M, Egginton S, Gordon D, et al. A pivotal phase III, randomised, placebo-controlled study of belimumab in patients with systemic lupus erythematosus located in China, Japan and South Korea. Ann Rheum Dis 2018;77:355-63.

16. Furie R, Khamashta M, Merrill JT, Werth VP, Kalunian K, Brohawn P, et al; CD1013 Study Investigators. Anifrolumab, an 
anti-interferon- $\alpha$ receptor monoclonal antibody, in moderate-tosevere systemic lupus erythematosus. Arthritis Rheum 2017; 69:376-86.

17. Urowitz MB, Gladman DD. Contributions of observational cohort studies in systemic lupus erythematosus: the University of Toronto Lupus Clinic experience. Rheum Dis Clin North Am 2005; 31:211-21, v.

18. Gladman DD, Urowitz MB, Rahman P, Ibanez D, Tam LS. Accrual of organ damage over time in patients with systemic lupus erythematosus. J Rheumatol 2003;30:1955-9.

19. Gladman D, Ginzler E, Goldsmith C, Fortin P, Liang M, Urowitz $\mathrm{M}$, et al. The development and initial validation of the Systemic Lupus International Collaborating Clinics/American College of Rheumatology damage index for systemic lupus erythematosus. Arthritis Rheum 1996;39:363-9.

20. Gladman DD, Urowitz MB, Goldsmith CH, Fortin P, Ginzler E, Gordon C, et al. The reliability of the Systemic Lupus International Collaborating Clinics/American College of Rheumatology Damage Index in patients with systemic lupus erythematosus. Arthritis Rheum 1997;40:809-13.

21. Urowitz MB, Gladman DD, Tom BD, Ibanez D, Farewell VT. Changing patterns in mortality and disease outcomes for patients with systemic lupus erythematosus. J Rheumatol 2008;35:2152-8.

22. Gladman D, Ibanez D, Ruiz I, Urowitz M. Recommendations for frequency of visits to monitor systemic lupus erythematosus in asymptomatic patients: data from an observational cohort study. J Rheumatol 2013;40:630-3.

23. Sutton EJ, Davidson JE, Bruce IN. The Systemic Lupus International Collaborating Clinics (SLICC) Damage Index: a systematic literature review. Semin Arthritis Rheum 2013; 43:352-61.

24. Appenzeller S, Pereira DA, Costallat LT. Greater accrual damage in late-onset systemic lupus erythematosus: a long-term follow-up study. Lupus 2008;17:1023-8.

25. Maddison P, Farewell V, Isenberg D, Aranow C, Bae SC, Barr S, et al; Systemic Lupus International Collaborating Clinics. The rate and pattern of organ damage in late onset systemic lupus erythematosus. J Rheumatol 2002;29:913-7.

26. Ibañez D, Gladman DD, Urowitz MB. Adjusted mean Systemic Lupus Erythematosus Disease Activity Index-2K is a predictor of outcome in SLE. J Rheumatol 2005;32:824-7.

27. Ibañez D, Gladman D, Urowitz M. Summarizing disease features over time: II. Variability measures of SLEDAI-2K. J Rheumatol 2007;34:336-40.

28. Ward MM, Studenski S. Clinical manifestations of systemic lupus erythematosus: identification of racial and socioeconomic influences. Arch Internal Med 1990;150:849-53.

29. European Medicines Association. Guideline on clinical investigation of medicinal products for the treatment of systemic lupus erythematosus, cutaneous lupus and lupus nephritis. [Internet. Accessed August 6, 2020.] Available from: www.ema.europa.eu/ docs/en_GB/document_library/Scientific_guideline/2015/03/ WC500184889.pdf

30. van Vollenhoven RF, Mosca M, Bertsias G, Isenberg D, Kuhn A, Lerstrom K, et al. Treat-to-target in systemic lupus erythematosus: recommendations from an international task force. Ann Rheum Dis 2014;73:958-67. 